\title{
Laparoscopic surgery for locally advanced T4 colon cancer: the long- term outcomes and prognostic factors
}

\author{
Takahiro Yamanashi $^{1} \cdot$ Takatoshi Nakamura $^{1} \cdot$ Takeo Sato $^{1} \cdot$ Masanori Naito $^{1} \cdot$ Hirohisa Miura $^{1} \cdot$ Atsuko Tsutsui $^{1}$. \\ Masashi Shimazu' ${ }^{1}$ Masahiko Watanabe ${ }^{1}$
}

Received: 27 October 2017 / Accepted: 15 December 2017 / Published online: 29 December 2017

(c) The Author(s) 2017. This article is an open access publication

\begin{abstract}
Purpose For locally advanced pathological T4 (pT4) colon cancer, the safety and feasibility of laparoscopic procedures remain controversial. Therefore, this study aimed to assess short-term and long-term outcomes and to identify the prognostic factors in laparoscopic surgery for pT4 colon cancer.

Methods The study group included 130 patients who underwent laparoscopic radical resection for pT4 colon and rectosigmoid cancer from January 2004 through December 2012. The short-term outcomes, long-term outcomes, and prognostic factors in pT4 colon cancer were analyzed.

Results The median operative time was $205 \mathrm{~min}$, with a median blood loss of $10 \mathrm{ml}$. The conversion rate was $3.8 \%$, and 13 patients $(10.0 \%)$ had postoperative complications. The radial resection margin was positive in 1 patient $(0.8 \%)$. The median follow-up time was 73 months. The 5-year overall survival (OS) and recurrence-free survival (RFS) were 77.2 and $63.5 \%$, respectively. On a multivariate analysis, a male sex [hazard ratio (HR) 3.09, $p<0.001$ ], lymph node ratio $\geq 0.06$ (HR 2.35, $p=0.021$ ), tumor diameter $<38 \mathrm{~mm}$ (HR 2.57, $p=0.007$ ), and right-sided colon cancer (HR 2.11, $p=0.047$ ) were significantly related to a poor OS.

Conclusions These results suggest that laparoscopic surgery for pT4 colon cancer is safe and feasible, and the oncological outcomes are acceptable. Based on the present findings, select patients with locally advanced colon cancer should not be excluded from laparoscopic surgery.
\end{abstract}

Keywords Colorectal cancer $\cdot$ T4 colon cancer $\cdot$ Laparoscopic surgery $\cdot$ Long-term outcomes $\cdot$ Prognostic factors

\section{Introduction}

Laparoscopic surgery for advanced colorectal cancer has become widespread, with demonstrated short-term benefits and better long-term oncological outcomes than open surgery [1-10]. However, for locally advanced pathological T4 (pT4) colon cancer based on the American Joint Committee on Cancer (AJCC) TNM staging system [11], the safety and feasibility of laparoscopic procedures remain controversial. In pT4 colon cancer, technically demanding surgical procedures, including en bloc resection of adjacent infiltrated organs or structures, are generally required. It is well known

Masahiko Watanabe

intl-aff@kitasato-u.ac.jp

1 Department of Surgery, Kitasato University School of Medicine, 1-15-1 Kitasato, Minami-ku, Sagamihara, Kanagawa 252-0374, Japan that open multivisceral resection for pT4 colon cancer has a high postoperative morbidity and a high risk of microscopically positive surgical margins $[12,13]$. For these reasons, some authors consider pT4 colon cancer to be a relative contraindication to laparoscopic surgery that may result in prolonged operative time, an increased conversion rate, higher postoperative morbidity, and, most importantly, suboptimal oncological results [6].

There is a general lack of evidence-based literature concerning laparoscopic surgery for locally advanced colon cancer. Indeed, cases of clinical T4 (cT4) tumor, perforated tumor, and acute bowel obstruction were excluded in large randomized, controlled trials comparing the laparoscopic approach with the open approach for colorectal cancer [1-7]. Some retrospective studies have reported satisfactory surgical and oncological outcomes of laparoscopic surgery for $\mathrm{T} 4$ colon cancer [14-22], but these studies were relatively small series, or the duration of follow-up was short in some 
reports, and the prognostic factors of patients with pT4 colon cancer who underwent laparoscopic surgery were not reported.

Therefore, this study aimed to retrospectively assess the short-term and long-term outcomes and identify prognostic factors of laparoscopic resection for pT4 colon cancer, in a large series of 130 patients with a long median follow-up period of 73 months.

\section{Methods}

\section{Patients}

Laparoscopic surgery for advanced colorectal cancer has been performed in our hospital since 1995. This retrospective study was approved by the local ethics board. The study included 130 patients who underwent radical laparoscopic resection for pT4 colon and rectosigmoid (RS) cancer without transverse colon cancer, descending colon cancer, or RS cancer requiring low anterior resection, excluding those with distant metastases, from January 2004 through December 2012 at our institution. Patients with severe medical conditions or with definite contiguous organ involvement on preoperative imaging, including cT4b tumor, were also excluded.

All patients underwent a preoperative evaluation including a physical examination, colonoscopy with a biopsy, and chest-abdominopelvic computed tomography (CT) with contrast enhancement. In suspicious cases, positron emission tomography (PET) was performed to identify distant organ metastases. Preoperative laboratory data included a complete blood cell count, biochemical profile, and tumor marker [carcinoembryonic antigen (CEA)] levels. Patients with non-metastatic colon cancer did not receive neoadjuvant chemotherapy. Colonic obstruction was managed using preoperative endoscopic stent insertion followed by laparoscopic resection.

\section{Operative procedures and follow-up}

Patients underwent standard preoperative preparation. All laparoscopic surgeries were radical resections with a complete mesocolic excision and central vascular ligation by colorectal surgeons with extensive experience. Laparoscopic procedures were performed using a pure laparoscopic technique. The appropriate surgical procedures were selected based on tumor location as follows: ileocecal resection (ICR), right hemicolectomy (RHC), sigmoidectomy (SR), and anterior resection (AR). Extracorporeal anastomosis was performed for right-sided colon cancer. The extraction incision was shielded using a wound protector before the specimen was removed. Multivisceral en bloc resection with a 1-cm margin of normal tissue was performed for tumor with involvement to adjacent organs or structures.

After recovery from surgery, adjuvant chemotherapy by oncologists was recommended for patients with TNM stage III disease or those with unfavorable histopathological characteristics, unless there were contraindications related to a patient's performance status. All patients were followed regularly using an oncological follow-up program for at least 5 years after surgery or until death in cases of recurrence. Patients were followed-up every 3 months for the first 3 years and every 6 months thereafter. Blood test results, including CEA, were checked at each visit. Chest-abdominopelvic CT was performed annually. Colonoscopy was performed 1 year after surgery and every 2 years thereafter. If recurrence was suspected, magnetic resonance imaging (MRI) and/or PET-CT was used to confirm the diagnosis of metastases. Biopsies were selectively performed. Operation was considered for patients with good performance status with resectable recurrence. The follow-up time was calculated as the time interval from the operation until death and not until the last follow-up date.

\section{Study outcomes}

Patient age, sex, body mass index (BMI), American Society of Anesthesiologists (ASA) score, CEA level, clinical TNM staging, tumor location, operative procedure, anastomosis, operative time, blood loss, conversion to open surgery, number of harvested lymph nodes, lymph node ratio (LNR), histopathological TNM staging, lymphatic invasion, vascular invasion, tumor differentiation, tumor maximum diameter, radial resection margin, first flatus, duration of hospital stay, postoperative morbidity, mortality, adjuvant chemotherapy, and long-term oncological outcomes were obtained from the medical records. Conversion from laparoscopy to open surgery was defined as whenever the specimen extraction wound was enlarged for a reason other than delivery of the specimen. The ratio of the number of metastatic lymph nodes to the total number of harvested lymph nodes (LNR) has shown prognostic significance in colorectal cancer [23-26]. A receiver operating characteristic (ROC) curve analysis identified 0.06 as the best LNR cut-off value that had an impact on the overall survival (OS) in the present study, with an area under the curve (AUC) of 0.68. For the analysis of the prognosis, the cut-off value of each clinicopathological factor was determined using an ROC curve analysis as follows: age, 74 years; BMI, $21 \mathrm{~kg} / \mathrm{m}^{2}$; CEA, $4.8 \mathrm{ng} / \mathrm{ml}$; number of harvested lymph nodes, 17; maximum tumor diameter, $38 \mathrm{~mm}$; operative time, $230 \mathrm{~min}$; and blood loss, $35 \mathrm{ml}$. $\mathrm{pN} 2$ patients ( $\geq 4$ positive nodes) have been shown to have a poorer prognosis in stage III based on the AJCC TNM staging system than $\mathrm{pN} 1$ patients ( $\leq 3$ positive nodes) [27]. In the present study, $\mathrm{pN}$ was subdivided into $\mathrm{pN} 0-1$ and $\mathrm{pN} 2$. 
In addition, cases with vascular invasion have also shown a poor prognosis in colorectal cancer. A previous report showed that the degree of vascular invasion influences liver metastasis, local recurrence, and survival rates [28]. In the present study, lymphatic invasion and vascular invasion were divided into 4 grades: ly/v0, which included no evidence of vessel permeation by tumor cells; ly/v1, which included the possible or doubtful presence of vessel permeation; ly/v2, which included the definite presence of permeation to a few vessels; and ly/v3, which included the definite presence of permeation to many vessels. Furthermore, vascular invasion (or lymphatic invasion) was subdivided into v0-2 (or ly0-2) and v3 (or ly3) for the analysis of the prognosis.

Postoperative morbidity and mortality were defined as events occurring during the hospital stay or within 30 days after surgery. Postoperative complications were categorized by the Clavien-Dindo classification [29]. All such events were assessed by a clinician and documented prospectively in the database. The long-term oncological outcomes included recurrence, the OS, and the recurrence-free survival (RFS). Prognostic factors for the OS and RFS in pT4 colon cancer were analyzed using the clinicopathological parameters and perioperative outcomes.

\section{Statistical analyses}

Statistical analyses were performed using statistical software JMP pro 11 (SAS Institute Inc., Cary, NC, USA). Descriptive data are presented as the mean and standard deviation (SD), median and range, and number of patients and percentage. A significant difference was defined as a $p$ value $<0.05$. The OS and RFS at 5 years were analyzed using the Kaplan-Meier method and compared between subgroups using the log-rank test. Prognostic factors for the OS and RFS were analyzed by Cox regression hazard models, including all variables reaching $p$ values $<0.1$ on the univariate analyses.

\section{Results}

All 130 patients with pT4 colon and RS cancer who underwent radical laparoscopic resection between January 2004 and December 2012 were selected for study analyses with a median follow-up period of 73 months (range 12-162). The clinicopathological and perioperative findings for all 130 patients are summarized in Tables 1 and 2, respectively. The mean age was $64.2( \pm 11.5)$ years. There were 73 male patients (56.2\%) and 57 female patients (43.8\%). The mean CEA level was $9.7( \pm 14.0) \mathrm{ng} / \mathrm{ml}$. Tumor locations were the cecum in 25 patients (19.2\%), ascending colon in 30 patients (23.1\%), sigmoid colon in 63 patients (48.5\%), and RS colon in 12 patients $(9.2 \%)$. Right-sided colon cancer was present
Table 1 Clinicopathological characteristics of patients with pT4 colon and rectosigmoid cancer $(N=130)$

\begin{tabular}{|c|c|c|}
\hline Parameters & Categories & Number (\%) \\
\hline Age, mean $\pm S D$, years & & $64.2 \pm 11.5$ \\
\hline \multirow[t]{2}{*}{ Gender } & Male & $73(56.2)$ \\
\hline & Female & $57(43.8)$ \\
\hline Body mass index, mean \pm SD & & $22.3 \pm 3.1$ \\
\hline \multirow[t]{3}{*}{ ASA score ${ }^{\mathrm{a}}$} & 1 & $56(43.1)$ \\
\hline & 2 & $62(47.7)$ \\
\hline & 3 & $12(9.2)$ \\
\hline $\mathrm{CEA}$, mean $\pm \mathrm{SD}, \mathrm{ng} / \mathrm{ml}$ & & $9.7 \pm 14.0$ \\
\hline \multirow[t]{4}{*}{ Tumor location (1) } & Cecum & $25(19.2)$ \\
\hline & Ascending & $30(23.1)$ \\
\hline & Sigmoid & $63(48.5)$ \\
\hline & Rectosigmoid & $12(9.2)$ \\
\hline \multirow[t]{2}{*}{ Tumor location (2) } & Right-sided & $55(42.3)$ \\
\hline & Left-sided & $75(57.7)$ \\
\hline \multirow[t]{4}{*}{ Operative procedure } & ICR & $20(15.4)$ \\
\hline & RHC & 35 (26.9) \\
\hline & SR & $63(48.5)$ \\
\hline & AR & $12(9.2)$ \\
\hline \multirow[t]{2}{*}{ Anastomosis } & DST & $68(52.3)$ \\
\hline & FEEA & $62(47.7)$ \\
\hline \multirow[t]{2}{*}{ Depth of invasion (cT) } & cT3 & $32(24.6)$ \\
\hline & $\mathrm{cT} 4 \mathrm{a}$ & $98(75.4)$ \\
\hline \multirow[t]{3}{*}{ Lymph node metastasis $(\mathrm{cN})$} & cNO & $61(46.9)$ \\
\hline & $\mathrm{cN} 1$ & $64(49.2)$ \\
\hline & $\mathrm{cN} 2$ & $5(3.8)$ \\
\hline \multirow[t]{2}{*}{ Distant metastasis (cM) } & cM0 & $130(100.0)$ \\
\hline & cM1 & $0(0.0)$ \\
\hline \multirow[t]{4}{*}{ Clinical stage (UICC 7th) } & IIA & $25(19.2)$ \\
\hline & IIB & $36(27.7)$ \\
\hline & IIIB & $65(50.0)$ \\
\hline & IIIC & $4(3.1)$ \\
\hline \multirow[t]{2}{*}{ Depth of invasion (pT) } & pT4a & $125(96.2)$ \\
\hline & pT4b & $5(3.8)$ \\
\hline \multirow[t]{3}{*}{ Lymph node metastasis (pN) } & pNO & $47(36.2)$ \\
\hline & $\mathrm{pN} 1$ & $56(43.1)$ \\
\hline & $\mathrm{pN} 2$ & $27(20.8)$ \\
\hline \multirow[t]{2}{*}{ Distant metastasis (pM) } & pM0 & $130(100.0)$ \\
\hline & pM1 & $0(0.0)$ \\
\hline \multirow[t]{4}{*}{ Pathological stage (UICC 7th) } & IIB & $44(33.8)$ \\
\hline & IIC & $3(2.3)$ \\
\hline & IIIB & $56(43.1)$ \\
\hline & IIIC & $27(20.8)$ \\
\hline Harvested lymph nodes, mean \pm SD & & $19.9 \pm 9.3$ \\
\hline Lymph node ratio ${ }^{\mathrm{b}}$, mean $\pm \mathrm{SD}$ & & $0.12 \pm 0.16$ \\
\hline \multirow[t]{3}{*}{ Tumor differentiation } & Well & $39(30.0)$ \\
\hline & Moderately & $81(62.3)$ \\
\hline & Poorly & $10(7.7)$ \\
\hline
\end{tabular}


Table 1 (continued)

\begin{tabular}{lll}
\hline Parameters & Categories & Number (\%) \\
\hline Lymphatic invasion & ly0 & $16(12.3)$ \\
& ly1 & $54(41.5)$ \\
& ly2 & $45(34.6)$ \\
& ly3 & $15(11.5)$ \\
Vascular invasion & $\mathrm{v} 0$ & $2(1.5)$ \\
& $\mathrm{v} 1$ & $45(34.6)$ \\
& $\mathrm{v} 2$ & $50(38.5)$ \\
Tumor diameter, mean $\pm \mathrm{SD}, \mathrm{mm}$ & $\mathrm{v} 3$ & $33(25.4)$ \\
Radial resection margin & & $47.3 \pm 18.0$ \\
& Negative & $129(99.2)$ \\
Adjuvant chemotherapy & Positive & $1(0.8)$ \\
& Absence & $63(48.5)$ \\
& Presence & $67(51.5)$ \\
\hline
\end{tabular}

$I C R$ ileocecal resection, $R H C$ right hemicolectomy, $S R$ sigmoidectomy, $A R$ anterior resection, $D S T$ double stapling technique, FEEA functional end-to-end anastomosis, $S D$ standard deviation

${ }^{a}$ American Society of Anesthesiologists score

${ }^{\mathrm{b}}$ The ratio of metastatic lymph nodes to the total number of harvested lymph nodes

Table 2 Perioperative outcomes $(N=130)$

\begin{tabular}{ll}
\hline Parameters & Number $(\%)$ \\
\hline Operative time, median (range), min & $205(105-460)$ \\
Blood loss, median (range), ml & $10(5-655)$ \\
Conversion to open surgery & $5(3.8)$ \\
First flatus, median (range), day & $1(1-8)$ \\
Postoperative hospital stay, median (range), day & $7.5(4-278)$ \\
Mortality & $0(0.0)$ \\
Morbidity (Clavien-Dindo ${ }^{a} \geq$ Grade II) & $13(10.0)$ \\
Anastomotic leakage & $4(3.1)$ \\
Bowel obstruction & $2(1.5)$ \\
Wound infection & $7(5.4)$
\end{tabular}

${ }^{\mathrm{a}}$ Clavien-Dindo classification

in 55 patients (42.3\%), with left-sided colon cancer in 75 patients (57.7\%). The median operative time was 205 (range 105-460) min, with a median blood loss of 10 (range 5-655) $\mathrm{ml}$. Multivisceral resection was required in 16 patients $(12.3 \%)$, as follows: abdominal wall in 8 patients $(6.2 \%)$; retroperitoneal adipose tissue in 3 patients $(2.3 \%)$; partial resection of the bladder in 2 patients $(1.5 \%)$; small intestine in 1 patient $(0.8 \%)$; sigmoid colon in 1 patient $(0.8 \%)$; and seminal duct in 1 patient $(0.8 \%)$. Conversion from laparoscopy to open surgery was required in 5 patients (3.8\%) due to technical difficulties with multivisceral resection of the abdominal wall in 3 patients, the small intestine in 1 patient, and the sigmoid colon in 1 patient. The median first flatus was 1 day (range 1-8 days). The median postoperative hospital stay was 7.5 (range 4-278) days. Overall, 13 patients (10.0\%) had postoperative complications classified as Clavien-Dindo II and III, with anastomotic leakage in 4 patients (3.1\%), bowel obstruction in 2 patients (1.5\%), and wound infection in 7 patients $(5.4 \%)$. There were no cases of mortality at 30 days postoperatively. Pathological stage (pStage) was IIB in 44 patients (33.8\%), IIC in 3 patients (2.3\%), IIIB in 56 patients (43.1\%), and IIIC in 27 patients (20.8\%). A total of 83 patients $(63.8 \%)$ had lymph node metastases. The mean number of harvested lymph nodes was 19.9 ( \pm 9.3$)$. In 107 patients (82.3\%), more than 12 lymph nodes were harvested. The mean LNR was $0.12( \pm 0.16)$. The mean tumor maximum diameter was $47.3( \pm 18.0) \mathrm{mm}$. The radial resection margin was positive in 1 patient $(0.8 \%)$; although the $T$ factor of this patient was pT4a, it was difficult to maintain the operative field because of the presence of strong tumor-induced inflammatory adhesions. The R0 resection rate was $99.2 \%$ (129/130). Ultimately, 67 patients $(51.5 \%)$ received postoperative adjuvant chemotherapy. The chemotherapy rate for each pStage was as follows: $12.8 \%$ in pStage II (6/47 patients); $71.4 \%$ in pStage IIIB (40/56 patients); and $77.8 \%$ in pStage IIIC (21/27 patients).

The OS and RFS curves are shown in Fig. 1. The 5-year OS and RFS were 77.2 and $63.5 \%$, respectively. The pStage was subdivided into II, IIIB, and IIIC; the 5-year OS was $86.6 \%$ in II, $70.9 \%$ in IIIB, and $73.7 \%$ in IIIC, and the 5-year RFS was $87.2 \%$ in II, $53.5 \%$ in IIIB, and $41.7 \%$ in IIIC. Patients with $\mathrm{pStage}$ II had a significantly better prognosis than patients with IIIB ( $p=0.003$ for OS, $p<0.001$ for RFS) and IIIC ( $p=0.016$ for OS, $p<0.001$ for RFS). There were no significant differences in the OS and RFS between pStage IIIB and IIIC. Overall, 47 patients (36.2\%) had recurrences, involving the liver in 16 patients $(12.3 \%)$, peritoneum in 12 patients $(9.2 \%)$, lung in 11 patients $(8.5 \%)$, paraaortic region in 8 patients $(6.2 \%)$, local region in 5 patients (3.8\%), metachronous colorectal cancer in 3 patients $(2.3 \%)$, and ovary in 2 patients $(1.5 \%)$, including double-counted patients (Table 3 ).

The results of the univariate and multivariate analyses are shown in Tables 4 and 5, respectively. On univariate analyses for the OS, possible prognostic factors, including the age $(p=0.003)$, sex $(p=0.003)$, CEA $(p=0.011)$, tumor location $(p=0.068)$, LNR $(p<0.001)$, lymphatic invasion $(p=0.009)$, vascular invasion $(p=0.038)$, and tumor diameter $(p=0.047)$, were selected for multivariate analyses. For the RFS, the sex $(p=0.033)$, CEA $(p=0.070), \mathrm{pN}(p=0.045), \mathrm{LNR}(p<0.001)$, tumor differentiation $(p=0.097)$, lymphatic invasion $(p=0.003)$, vascular invasion $(p=0.025)$, and adjuvant chemotherapy $(p=0.024)$ were selected for multivariate analyses. The multivariate analyses showed that sex [male vs. female, hazard ratio (HR) 3.09, 95\% confidence interval (CI) $1.58-6.48, p<0.001]$, LNR $(\geq 0.06$ vs. $<0.06$, HR 2.35 , 

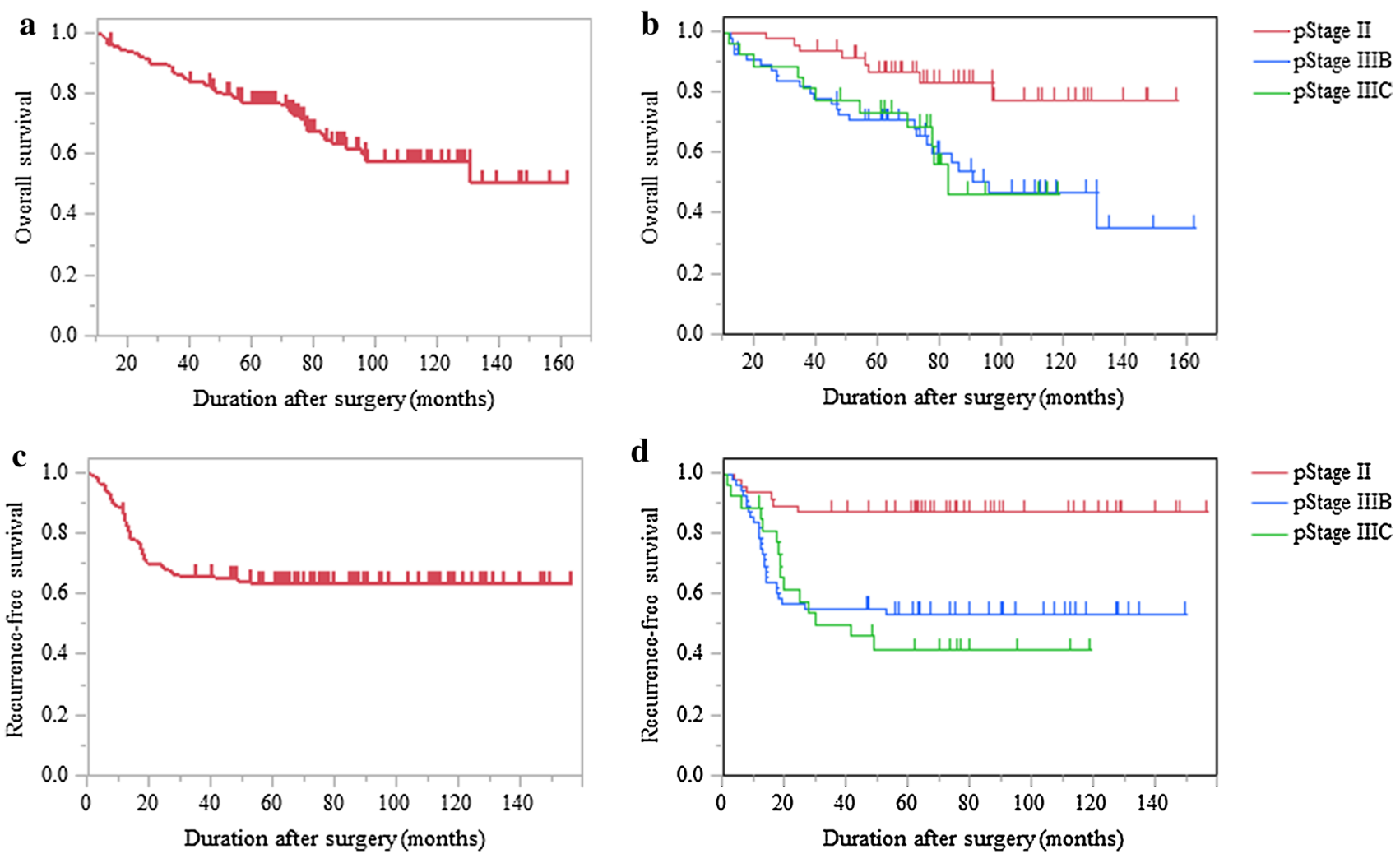

Fig. 1 The survival of patients with pT4 colon and rectosigmoid cancer $(N=130)$. a The overall survival (OS) in all cases. b OS, pStage is subdivided into II, IIIB, and IIIC. c The recurrence-free survival (RFS) in all cases. d RFS, pStage is subdivided into II, IIIB, and

IIIC. Patients with pStage II had a significantly better prognosis than patients with IIIB ( $p=0.003$ for OS, $p<0.001$ for RFS) and IIIC $(p=0.016$ for OS, $p<0.001$ for RFS $)$

95\% CI 1.13-5.17, $p=0.021$ ), tumor diameter (<38 vs. $\geq 38 \mathrm{~mm}$, HR 2.57, 95\% CI 1.30-5.09, $p=0.007)$, and tumor location (right-sided vs. left-sided, HR 2.11, $95 \%$ CI 1.01-4.46, $p=0.047$ ) were significant independent prognostic factors for the OS. Furthermore, for the RFS, the sex (male vs. female, HR 2.02, 95\% CI 1.09-3.90, $p=0.026)$ and LNR ( $\geq 0.06$ vs. $<0.06$, HR $4.76,95 \%$ CI 2.08-11.64, $p<0.001)$ were significant independent prognostic factors. Subgroup analyses for the OS and RFS were done for the sex (male vs. female) and LNR $(\geq 0.06$ vs. $<0.06)$. All patients were subdivided into 4 groups as follows: female with $\mathrm{LNR}<0.06$, male with $\mathrm{LNR}<0.06$, female with $L N R \geq 0.06$, and male with $L N R \geq 0.06$. In addition, all patients were subdivided into 2 groups as male with LNR $\geq 0.06$ and others. The OS and RFS curves and rates are shown in Fig. 2 and Table 6, respectively. Female patients with LNR $<0.06$ had a significantly better OS and RFS than male patients with LNR $\geq 0.06$ (both $p<0.001)$. Furthermore, male patients with LNR $\geq 0.06$ had a significantly worse OS and RFS than the others (both $p<0.001$ ).

\section{Discussion}

The guidelines from the European Association of Endoscopic Surgery (EAES) recommend that preoperative T4 colorectal cancer be treated with open resection [30]. In general, pT4 colon cancer requires technically demanding surgical procedures, including en bloc resection of adjacent infiltrated organs or structures. Open multivisceral resection for $\mathrm{pT} 4$ colon cancer is known to have a high postoperative morbidity and a high risk of microscopically positive surgical margins [12, 13]. Furthermore, it is often difficult to distinguish between tumor-induced inflammatory adhesions and pathological tumor involvement for locally advanced colon cancer, especially by laparoscopy. Some authors have argued that pT4 tumor can raise the risk of conversion to open surgery. In the COLOR trial, the overall conversion rate was $17 \%$, whereas $50 \%$ of patients with pT4 tumor required conversion to open surgery [6]. Regarding previous reports with only T4 colorectal cancer, the conversion rate ranged from 5.6 to 
Table 3 Initial recurrence site in pT4 colon and rectosigmoid cancer $(N=130)$

\begin{tabular}{lrl}
\hline & Number (\%) & Surgical procedure \\
\hline Recurrence (total) & $47 / 130(36.2)$ & \\
Liver & $16(12.3)$ & Resection in 5, RFA ${ }^{\mathrm{a}}$ in 1 \\
Peritoneum & $12(9.2)$ & Resection in 1 \\
Lung & $11(8.5)$ & Resection in 3 \\
Paraaortic region & $8(6.2)$ & Resection in 1 \\
Local region & $5(3.8)$ & Resection in 1, enteros- \\
& & tomy in 2 \\
Metachronous CRC & $3(2.3)$ & Resection in 2 \\
Ovary & $2(1.5)$ & Resection in 1 \\
Stage II & $6 / 47(12.8)$ & \\
Liver & $3(2.3)$ & Resection in 1 \\
Peritoneum & $1(0.8)$ & Absence \\
Lung & $2(1.5)$ & Absence \\
Paraaortic region & $1(0.8)$ & Absence \\
Local region & $1(0.8)$ & Enterostomy in 1 \\
Metachronous CRC & $0(0.0)$ & Absence \\
Ovary & $0(0.0)$ & Absence \\
Stage III & $3(2.3)$ & Resection in 2 \\
Liver & $2(1.5)$ & Resection in 1 \\
Peritoneum & $13(10.0)$ & Resection in 4, RFA in 1 \\
Lung & $11(8.5)$ & Resection in 1 \\
Paraaortic region & $9(6.9)$ & Resection in 3 \\
Local region & $4(5.4)$ & Resection in 1 \\
Metachronous CRC & & \\
Ovary & $41 / 83)$ & Resection in 1, enteros- \\
\hline
\end{tabular}

$C R C$ colorectal cancer

Including double-count patients

${ }^{\text {a}}$ Radio frequency ablation

$24.7 \%$ [14-22, 31, 32]. In the present study, conversion to open surgery was required in only 5 patients $(3.8 \%)$ with pT4 colon cancer. The Laparoscopic Colorectal Surgery Study Group reported a significantly lower conversion rate in high-volume centers than in low-volume centers [33]. Another previous report showed that the factors influencing conversion were 2 adherent organs $(p=0.028)$ and clinical suspicion of direct invasion to adjacent organs (cT4b) ( $p=0.076)$ [34]. In the present study, the low conversion rate was likely due to the extensive experience of the colorectal surgical team and the exclusion of patients diagnosed with cT4b tumor on preoperative imaging. Indeed, although this study focused on pT4 cancer, the median operative time of $205 \mathrm{~min}$, blood loss of $10 \mathrm{ml}$, and postoperative hospital stay of 7.5 days were comparable to those of large randomized trials of colorectal cancer of all TNM stages [4, 8]. Furthermore, some authors have shown no marked differences in morbidity and mortality between laparoscopic procedures and open surgery for
T4 colorectal cancer [16-21, 32]. Morbidity rates ranged from 7.7 to $30 \%$ in these reports. In the present study, 13 patients $(10.0 \%)$ had postoperative complications classified as Clavien-Dindo II and III, and there were no deaths at 30 days postoperatively.

The mean number of harvested lymph nodes was 19.9 $( \pm 9.3)$ in the present study, and more than 12 lymph nodes were harvested in 107 patients (82.3\%), which is in keeping with the guidelines of the National Comprehensive Cancer Network 2009 [35]. In the present study, 1 patient $(0.8 \%)$ had a positive radial resection margin. R0 resection is generally recognized as the most important factor for achieving the best results in terms of local recurrence and the survival in T4 colorectal cancer $[12,36]$. In the COLOR trial, $1 \%$ of patients with pT3 (4/350) had R1 resection, whereas $20 \%$ of patients with pT4 (6/30) had R1 resection [6]. In addition, a study reported the positive margin status for pT4 colon cancer for laparoscopic procedures and open surgery using a large US national surgical database [31]; they showed that patients who underwent laparoscopic colorectal resection did not have a significantly higher positive margin rate than patients who underwent open surgery (laparoscopy $26.2 \%$ vs. open surgery $24.3 \%$, OR $1.10, p=0.54)$. The present $\mathrm{R} 1$ rate is extremely low compared with previous reports, probably due to the exclusion of patients diagnosed as definitely having $\mathrm{T} 4 \mathrm{~b}$ tumor on preoperative imaging and the extensive experience of the dedicated laparoscopic surgical teams. These results suggest that laparoscopic surgery for pT4 colon cancer is safe and feasible with respect to surgical outcomes, with favorable conversion, morbidity, and R0 resection rates.

According to the large randomized trials for colorectal cancer, the 5-year OS and disease-free survival (or RFS) rates of laparoscopic procedures were 55-91 and 57-79\%, respectively $[5,7,10]$. Despite including only pT4 cancer cases, the 5-year survival rates were comparable in the present study. The overall recurrence rate was $36.2 \%$ (47/130). This higher rate of recurrence can be explained by the oncological biology of pT4 tumors, which have an increased tendency for lymph node and systemic spread [37]. The low chemotherapy rate of only $51.5 \%$ also adversely affected the survival in these patients. This low chemotherapy rate was due to an extremely low rate of induction of adjuvant chemotherapy in pStage II (12.8\%, patients of $6 / 47)$. The peritoneal recurrence rate was $9.2 \%(12 / 130)$ in the present study. T4 tumor with adherence caused by inflammation requires en bloc resection. The easier dissection may lead to a detrimental effect on the dissemination of tumor cells [36]. There is a possibility that this higher rate of peritoneal recurrence is due to careless surgical procedures, and it can also be explained by the oncological biology of pT4 tumors.

A systematic review of laparoscopic surgery for T4 colon cancer was recently reported [32]. It included 13 
Table 4 Univariate prognostic analyses in pT4 colon and rectosigmoid cancer $(N=130)$

\begin{tabular}{|c|c|c|c|c|c|c|}
\hline Parameters & Categories & Number (\%) & 5-year OS (\%) & $p$ value & 5-year RFS (\%) & $p$ value \\
\hline \multirow[t]{2}{*}{ Age (years) } & $\geq 74$ & $30(23.1)$ & 59.0 & 0.003 & 63.3 & 0.791 \\
\hline & $<74$ & $100(76.9)$ & 82.7 & & 63.6 & \\
\hline \multirow[t]{2}{*}{ Gender } & Male & $73(56.2)$ & 70.5 & 0.003 & 55.5 & 0.033 \\
\hline & Female & $57(43.8)$ & 85.7 & & 73.6 & \\
\hline \multirow[t]{2}{*}{ Body mass index } & $\geq 21$ & $82(63.1)$ & 77.7 & 0.103 & 60.4 & 0.388 \\
\hline & $<21$ & $48(36.9)$ & 76.5 & & 68.8 & \\
\hline \multirow[t]{2}{*}{ ASA score ${ }^{a}$} & $1 / 2$ & $118(90.8)$ & 78.3 & 0.178 & 64.0 & 0.597 \\
\hline & 3 & $12(9.2)$ & 66.7 & & 58.3 & \\
\hline \multirow[t]{2}{*}{ CEA (ng/ml) } & $\geq 4.8$ & $60(46.2)$ & 67.8 & 0.011 & 55.8 & 0.070 \\
\hline & $<4.8$ & $70(53.8)$ & 85.5 & & 69.9 & \\
\hline \multirow[t]{2}{*}{ Tumor location } & Right-sided & $55(42.3)$ & 64.1 & 0.068 & 65.1 & 0.913 \\
\hline & Left-sided & $75(57.7)$ & 86.5 & & 62.5 & \\
\hline \multirow[t]{2}{*}{ Anastomosis } & DST & $68(52.3)$ & 86.6 & 0.200 & 60.1 & 0.609 \\
\hline & FEEA & $62(47.7)$ & 66.6 & & 67.5 & \\
\hline \multirow[t]{2}{*}{$\mathrm{cT}$} & cT3 & $32(24.6)$ & 74.2 & 0.824 & 65.3 & 0.822 \\
\hline & cT4a & $98(75.4)$ & 78.2 & & 62.9 & \\
\hline \multirow[t]{2}{*}{$\mathrm{cN}$} & $\mathrm{cN} 0 / 1$ & $125(96.2)$ & 77.2 & 0.485 & 63.9 & 0.617 \\
\hline & $\mathrm{cN} 2$ & $5(3.8)$ & 80.0 & & 50.0 & \\
\hline \multirow[t]{2}{*}{ pT } & pT4a & $125(96.2)$ & 76.4 & $0.280^{\mathrm{b}}$ & 62.0 & $0.128^{\mathrm{b}}$ \\
\hline & pT4b & $5(3.8)$ & 100.0 & & 100.0 & \\
\hline \multirow[t]{2}{*}{$\mathrm{pN}$} & $\mathrm{pN} 0 / 1$ & $103(79.2)$ & 78.2 & 0.275 & 68.8 & 0.045 \\
\hline & $\mathrm{pN} 2$ & $27(20.8)$ & 73.7 & & 41.7 & \\
\hline \multirow[t]{2}{*}{ Harvested lymph nodes } & $\geq 17$ & $79(60.8)$ & 81.9 & 0.169 & 64.1 & 0.871 \\
\hline & $<17$ & $51(39.2)$ & 70.4 & & 62.6 & \\
\hline \multirow[t]{2}{*}{ Lymph node ratio $^{c}$} & $\geq 0.06$ & $67(51.5)$ & 69.6 & $<0.001$ & 42.2 & $<\mathbf{0 . 0 0 1}$ \\
\hline & $<0.06$ & $63(48.5)$ & 85.3 & & 85.7 & \\
\hline \multirow[t]{2}{*}{ Tumor differentiation } & Well/moderately & $120(92.3)$ & 78.8 & 0.135 & 65.7 & 0.097 \\
\hline & Poorly & $10(7.7)$ & 56.3 & & 34.3 & \\
\hline \multirow[t]{2}{*}{ Lymphatic invasion } & $\operatorname{ly} 0 / 1 / 2$ & $115(88.5)$ & 80.6 & 0.009 & 68.5 & 0.003 \\
\hline & ly3 & $15(11.5)$ & 50.6 & & 21.8 & \\
\hline \multirow[t]{2}{*}{ Vascular invasion } & $\mathrm{v} 0 / 1 / 2$ & $97(74.6)$ & 83.2 & 0.038 & 68.6 & 0.025 \\
\hline & v3 & $33(25.4)$ & 59.4 & & 48.5 & \\
\hline \multirow[t]{2}{*}{ Tumor diameter (mm) } & $\geq 38$ & $87(66.9)$ & 79.8 & 0.047 & 67.5 & 0.217 \\
\hline & $<38$ & $43(33.1)$ & 71.9 & & 55.4 & \\
\hline \multirow[t]{2}{*}{ Adjuvant chemotherapy } & Absence & $63(48.5)$ & 78.9 & 0.602 & 74.4 & $\mathbf{0 . 0 2 4}$ \\
\hline & Presence & $67(51.5)$ & 75.7 & & 53.1 & \\
\hline \multirow[t]{2}{*}{ Operative time (min) } & $\geq 230$ & $40(30.8)$ & 79.1 & 0.506 & 61.4 & 0.855 \\
\hline & $<230$ & $90(69.2)$ & 76.4 & & 64.3 & \\
\hline \multirow[t]{2}{*}{ Blood loss (ml) } & $\geq 35$ & $39(30.0)$ & 81.6 & 0.401 & 71.3 & 0.318 \\
\hline & $<35$ & $91(70.0)$ & 75.5 & & 60.2 & \\
\hline \multirow[t]{2}{*}{ Conversion to open surgey } & Absence & $125(96.2)$ & 77.2 & 0.782 & 62.2 & $0.156^{\mathrm{b}}$ \\
\hline & Presence & $5(3.8)$ & 80.0 & & 100.0 & \\
\hline \multirow{2}{*}{$\begin{array}{l}\text { Morbidity (Clavien-Dindo }{ }^{\mathrm{d}} \geq \\
\text { Grade II) }\end{array}$} & Absence & $117(90.0)$ & 77.3 & 0.456 & 62.0 & 0.292 \\
\hline & Presence & $13(10.0)$ & 76.2 & & 76.9 & \\
\hline
\end{tabular}

$D S T$ double stapling technique, FEEA functional end-to-end anastomosis, RFS recurrence-free survival, $O S$ overall survival

Bold values was defined reaching $\mathrm{p}$ values $<0.1$ in all variables

${ }^{a}$ American Society of Anesthesiologists score

${ }^{b}$ Log-rank-test

${ }^{\mathrm{c}}$ The ratio of metastatic lymph nodes to total number of harvested lymph nodes

${ }^{\mathrm{d}}$ Clavien-Dindo classification 
Table 5 Multivariate prognostic analyses in pT4 colon and rectosigmoid cancer $(N=130)$

\begin{tabular}{|c|c|c|c|}
\hline Prognostic factors & Hazard ratio & $95 \%$ CI & $p$ value \\
\hline \multicolumn{4}{|l|}{ OS } \\
\hline Age $(\geq 74$ against $<74)$ (years) & 1.75 & $0.80-3.72$ & 0.159 \\
\hline Gender (male against female) & 3.09 & $1.58-6.48$ & $<0.001$ \\
\hline CEA $(\geq 4.8$ against $<4.8)(\mathrm{ng} / \mathrm{ml})$ & 1.64 & $0.87-3.17$ & 0.128 \\
\hline Tumor location (right-sided against left sided) & 2.11 & $1.01-4.46$ & $\mathbf{0 . 0 4 7}$ \\
\hline Lymph node ratio $^{\mathrm{a}}(\geq 0.06$ against $<0.06)$ & 2.35 & $1.13-5.17$ & 0.021 \\
\hline Lymphatic invasion (ly3 against ly0/1/2) & 1.88 & $0.82-4.03$ & 0.132 \\
\hline Vascular invasion (v3 against v0/1/2) & 1.91 & $0.96-3.70$ & 0.066 \\
\hline Tumor diameter $(<38$ against $\geq 38)(\mathrm{mm})$ & 2.57 & $1.30-5.09$ & 0.007 \\
\hline \multicolumn{4}{|l|}{ RFS } \\
\hline Gender (male against female) & 2.02 & $1.09-3.90$ & 0.026 \\
\hline CEA $(\geq 4.8$ against $<4.8)(\mathrm{ng} / \mathrm{ml})$ & 1.52 & $0.83-2.84$ & 0.176 \\
\hline $\mathrm{pN}(\mathrm{pN} 0 / 1$ against $\mathrm{pN} 2)$ & 1.32 & $0.66-2.71$ & 0.429 \\
\hline Lymph node ratio $^{\mathrm{a}}(\geq 0.06$ against $<0.06)$ & 4.76 & $2.08-11.64$ & $<0.001$ \\
\hline Tumor differentiation (well/moderately against poorly) & 1.20 & $0.40-4.05$ & 0.754 \\
\hline Lymphatic invasion (ly3 against ly0/1/2) & 2.18 & $0.86-5.00$ & 0.096 \\
\hline Vascular invasion (v3 against v0/1/2) & 1.49 & $0.75-2.83$ & 0.248 \\
\hline Adjuvant chemotherapy (absence against presence) & 1.05 & $0.52-2.06$ & 0.880 \\
\hline
\end{tabular}

$C I$ confidence interval, $R F S$ recurrence-free survival, $O S$ overall survival

${ }^{a}$ The ratio of metastatic lymph nodes to total number of harvested lymph nodes
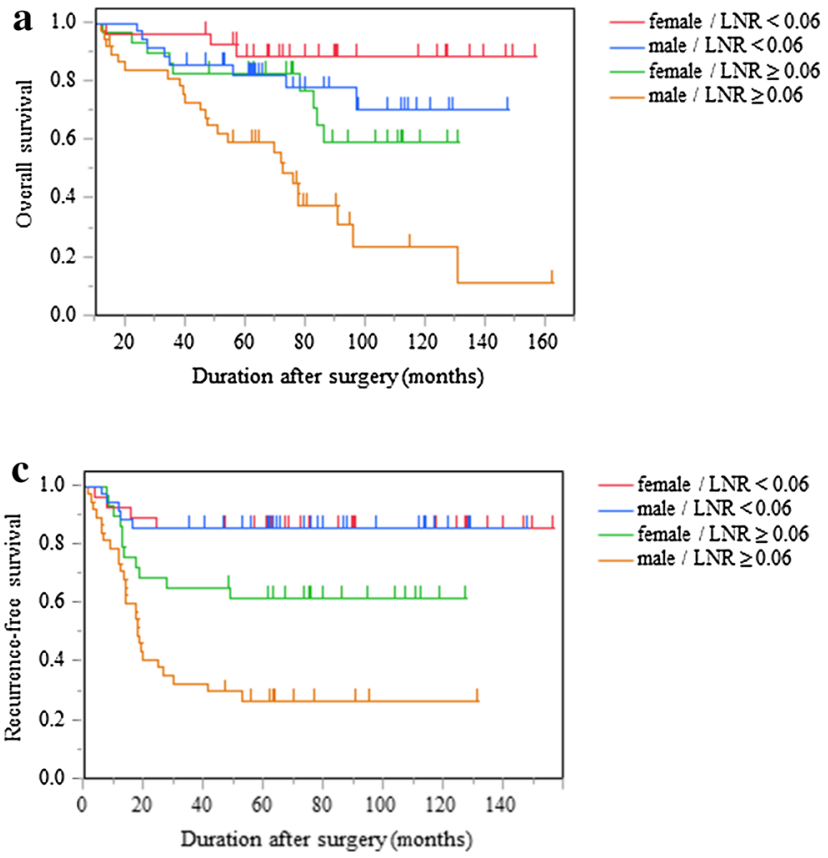

Fig. 2 The survival of patients with pT4 colon and rectosigmoid cancer in a subgroup analysis $(N=130)$. a OS, all cases are subdivided into 4 groups as follows: female with $\mathrm{LNR}<0.06$, male with $\mathrm{LNR}<0.06$, female with $\mathrm{LNR} \geq 0.06$, and male with $\mathrm{LNR} \geq 0.06$. b OS, all cases are subdivided into 2 groups as follows: male with LNR $\geq 0.06$, and others. $\mathbf{c}$ RFS, all cases are subdivided into 4 groups as follows: female with $\mathrm{LNR}<0.06$, male with $\mathrm{LNR}<0.06$, female with $\mathrm{LNR} \geq 0.06$, and male with $\mathrm{LNR} \geq 0.06$. d RFS, all cases are
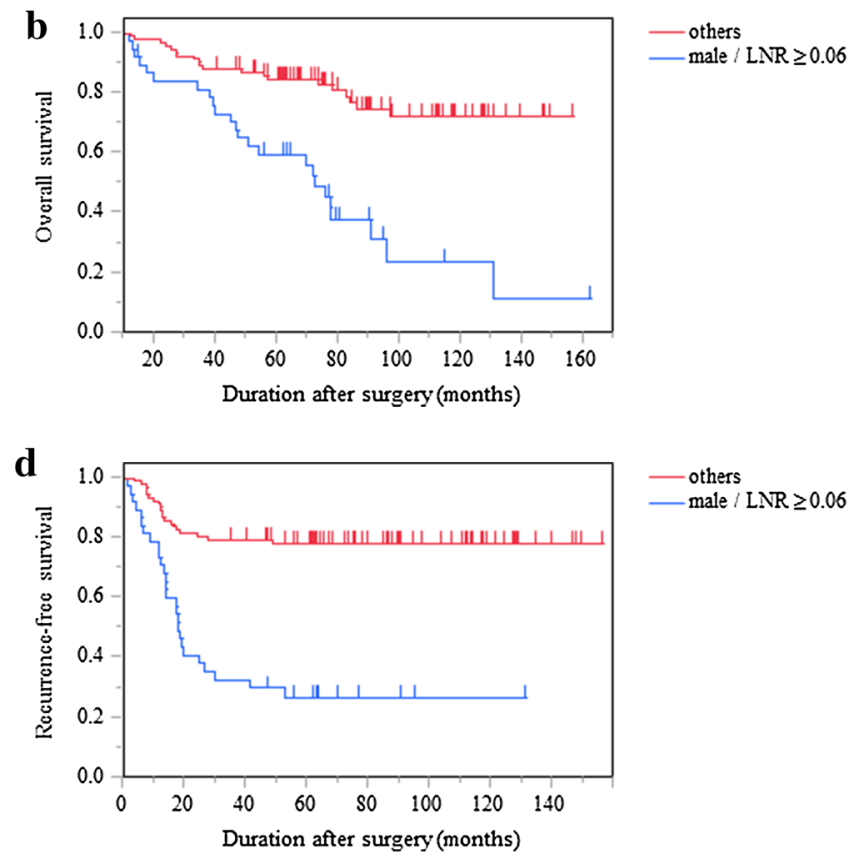

subdivided into 2 groups as follows: male with $\mathrm{LNR} \geq 0.06$, and others. $L N R$ lymph node ratio, the ratio of the number of metastatic lymph nodes to the total number of harvested lymph nodes. Female patients with LNR $<0.06$ had a significantly better OS and RFS than male patients with $\mathrm{LNR} \geq 0.06$ (both $p<0.001$ ). Male patients with LNR $\geq 0.06$ had a significantly worse OS and RFS than the others (both $p<0.001$ ) 
Table 6 Survival rates of patients with pT4 colon and rectosigmoid cancer in a subgroup analysis $(N=130)$

\begin{tabular}{llllll}
\hline Parameters & Number $(\%)$ & 5 -OS $(\%)$ & $p$ value & 5-RFS $(\%)$ & $p$ value \\
\hline Female/LNR $<0.06$ & $28(21.5)$ & 88.7 & $<0.001$ & 85.7 & $<0.001$ \\
Male/LNR $<0.06$ & $35(26.9)$ & 82.4 & & 85.7 & \\
Female/LNR $\geq 0.06$ & $29(22.3)$ & 82.8 & & 61.7 & \\
Male/LNR $\geq 0.06$ & $38(29.2)$ & 59.6 & & 27.0 & \\
Others & $92(70.8)$ & 84.5 & $<0.001$ & 78.2 & $<0.001$ \\
Male/LNR $\geq 0.06$ & $38(29.2)$ & 59.6 & & 27.0 & \\
\hline
\end{tabular}

$L N R$ lymph node ratio, the ratio of metastatic lymph nodes to the total number of harvested lymph nodes, $R F S$ recurrence-free survival, $O S$ overall survival observational cohort studies published between 2012 and 2017 , consisting of a total of 1217 patients who underwent laparoscopic procedures and 1357 who underwent open surgery. T4 staging included both pT4 and cT4. There were no significant differences between the rates of laparoscopic procedure and open surgery in oncological outcomes, including the radicality of resection, and any survival measures. Furthermore, the rate of postoperative complications was significantly lower after laparoscopic surgery than after open surgery (RR $0.65, p<0.001)$. However, the authors cautiously concluded that laparoscopic procedures for $\mathrm{T} 4 \mathrm{a}$ tumor might be safe, whereas they seem less appropriate for $\mathrm{T} 4 \mathrm{~b}$ tumors requiring multivisceral resection, because the current literature does not provide a definitive answer on the oncological safety of minimally invasive surgery for locally advanced colon cancer. Furthermore, according to a large randomized trial for colorectal cancer, JCOG 0404, patients with cT4 who underwent laparoscopic surgery tended to show a worse survival than those in the open surgery group (HR 1.27, 95\% CI 0.68-2.34) [10]. These results suggest that patients with T4b on surgical findings should be excluded from the laparoscopic approach.

In previous reports, the prognostic factors of laparoscopic surgery for pT4 colorectal cancer were not determined. In the present study, the multivariate analyses showed that a male sex (HR 3.09, 95\% CI 1.58-6.48, $p<0.001$ for OS; HR 2.02, 95\% CI 1.09-3.90, $p=0.026$ for RFS), LNR $\geq 0.06$ (HR 2.35, 95\% CI 1.13-5.17, $p=0.021$ for OS; HR 4.76, 95\% CI 2.08-11.64, $p<0.001$ for RFS), tumor maximum diameter $<38$ (HR 2.57, 95\% CI 1.30-5.09, $p=0.007$ for OS), and right-sided colon cancer (HR 2.11, 95\% CI 1.01-4.46, $p=0.047$ for OS) were significant independent factors related to a poor prognosis. Furthermore, in subgroup analyses, male patients with $\mathrm{LNR} \geq 0.06$ had a significantly worse OS and RFS (both $p<0.001$ ). For the vast majority of cancers, the age-adjusted mortality rates are higher among male patients than females [38]. Furthermore, the survival after colorectal cancer resection is longer in female than in male patients [39, 40]. In previous reports using the Surveillance, Epidemiology and End Results (SEER) database, although female patients presented more emergently and at an older age and received less aggressive medical treatment than males, which is associated with a poorer long-term survival, they had a longer survival duration than male patients with colorectal cancer (HR 0.80, $p<0.001$ ) [40]. Anatomy is unlikely to explain the differences in the survival because there are few differences in the technical difficulty of colon resection between male and female patients. Some authors speculate that differences in the circulating hormones or in the immunologic response to tumor between male and female patients may have been responsible for the survival advantage in female patients [39, 41-43]. They argued that a poor survival rate in male patients may be the result of an ongoing inflammatory response in the form of elevated $\mathrm{C}$-reactive protein levels. Indeed, elevated C-reactive protein levels are more detrimental in male patients than in female ones $[39,41]$. Other authors speculate that circulating estrogen stimulates a protective immune response to a tumor, whereas circulating testosterone results in a detrimental immune response [42, 43].

LNR has shown prognostic significance in colorectal cancer [23-26]. The conventional staging system for patients with colorectal cancer is based on the AJCC TNM staging system [11]. This staging is based on the total number of positive nodes and the depth of tumor invasion and is used as a prognostic tool. Several studies have directly compared LNR to N staging of TNM and found LNR to be superior in the staging of colon cancer [23-25]. In a previous report, LNR was a valuable prognostic factor in nodepositive colon cancer for laparoscopic surgery [26]. Those authors showed that patients with $\mathrm{LNR}<0.13$ had the same long-term outcomes as stage II node-negative patients. In the present study, despite a different LNR cut-off value using an ROC curve analysis, pStage III patients with $\mathrm{LNR}<0.06$ had similar long-term outcomes to pStage II patients $(81.3$ vs. $86.6 \%, p=0.772$ for the 5-year OS, data not shown). In the subgroup analyses, the group of male patients with LNR $\geq 0.06$ tended to have a worse prognosis than male patients with pStage IIIC (59.6 vs. $73.7 \%, p=0.152$ for the 5-year OS, data not shown).

Whether or not the tumor size significantly predicts the prognosis in colorectal cancer remains controversial. Some 
authors have shown that the tumor size that reflected the horizontal growth, which was correlated with advanced stage, and was an independent prognostic factor in colon cancer on multivariate analyses $[44,45]$. Generally, it is recognized that the survival decreases with increasing tumor size. However, some reports have shown that a small tumor size was an unfavorable prognostic factor, with a decreased survival, in colon cancer $[45,46]$. They showed that the 8-year causespecific survival (CSS) of patients with stage IIA colon cancer was significantly lower with tumor size $\leq 25 \mathrm{~mm}$ than with tumor size $>26 \mathrm{~mm}(p=0.003)$ [45]. In addition, in reports using the SEER database, very small breast cancer with positive lymph node involvement had an increased cancer-specific mortality compared with large tumors [47]. As a potential explanation of the present findings, we hypothesized that a small tumor size $(<38 \mathrm{~mm})$ may be a surrogate marker for biological aggressiveness, resulting in an inferior OS compared with larger tumors, and indicating that the initial biological heterogeneity of colon cancers determines a tumor's distinct growth pattern and invasive and metastatic abilities ( 71.9 vs. $79.8 \%, p=0.040$ for the 5 -year OS, data not shown). These results suggest that patients with such poor prognostic factors may need stronger postoperative or preoperative adjuvant chemotherapy.

In conclusion, while this study was limited by being a retrospective study performed at a single institution, its results suggest that laparoscopic surgery for locally advanced pT4 colon cancer is safe and feasible, does not increase the conversion rate, does not increase the postoperative morbidity, and has oncological outcomes that are acceptable. Although there is still room for improvement in patients with poor prognostic factors, based on the present findings and the availability of a colorectal surgical team with appropriate expertise, select patients with locally advanced colon cancer should not be excluded from laparoscopic surgery. The criteria for the selection of patients and the level of surgeon experience must be defined more precisely in future prospective studies.

\section{Compliance with ethical standards}

Conflict of interest Takahiro Yamanashi and the other co-authors have no conflicts of interest.

Open Access This article is distributed under the terms of the Creative Commons Attribution 4.0 International License (http://creativecommons.org/licenses/by/4.0/), which permits unrestricted use, distribution, and reproduction in any medium, provided you give appropriate credit to the original author(s) and the source, provide a link to the Creative Commons license, and indicate if changes were made.

\section{References}

1. Lacy AM, García-Valdecasas JC, Delgado S, Castells A, Taurá P, Piqué JM, et al. Laparoscopy-assisted colectomy versus open colectomy for treatment of non-metastatic colon cancer: a randomised trial. Lancet. 2002;359:2224-9.

2. Nelson H, Sargent DJ, Wieand HS, Fleshman J, Anvari M, Stryker SJ, et al. A comparison of laparoscopically assisted and open colectomy for colon cancer. N Engl J Med. 2004;350:2050-9.

3. Guillou PJ, Quirke P, Thorpe H, Walker J, Jayne DG, Smith $\mathrm{AMH}$, et al. Short-term endpoints of conventional versus laparoscopic-assisted surgery in patients with colorectal cancer (MRC CLASICC trial): multicentre, randomised controlled trial. Lancet. 2005;365:1718-26.

4. Veldkamp R, Kuhry E, Hop WC, Jeekel J, Kazemier G, Bonjer $\mathrm{HJ}$, et al. Laparoscopic surgery versus open surgery for colon cancer: short-term outcomes of a randomised trial. Lancet Oncol 2005;6:477-84.

5. Fleshman J, Sargent DJ, Green E, Anvari M, Stryker SJ, Beart $\mathrm{RW} \mathrm{Jr}$, et al. Laparoscopic colectomy for cancer is not inferior to open surgery based on 5-year data from the COST Study Group trial. Ann Surg 2007;246:655-62 (discussion 62-4).

6. Buunen M, Veldkamp R, Hop WC, Kuhry E, Jeekel J, Haglind E, et al. Survival after laparoscopic surgery versus open surgery for colon cancer: long-term outcome of a randomised clinical trial. Lancet Oncol. 2009;10:44-52.

7. Jayne DG, Thorpe HC, Copeland J, Quirke P, Brown JM, Guillou PJ. Five-year follow-up of the Medical Research Council CLASICC trial of laparoscopically assisted versus open surgery for colorectal cancer. Br J Surg. 2010;97:1638-45.

8. Yamamoto S, Inomata M, Katayama H, Mizusawa J, Etoh T, Konishi F, et al. Short-term surgical outcomes from a randomized controlled trial to evaluate laparoscopic and open D3 dissection for stage II/III colon cancer: Japan Clinical Oncology Group Study JCOG 0404. Ann Surg. 2014;260:23-30.

9. Matsumoto S, Bito S, Fujii S, Inomata M, Saida Y, Murata K, et al. Prospective study of patient satisfaction and postoperative quality of life after laparoscopic colectomy in Japan. Asian J Endosc Surg 2016;9:186-91.

10. Kitano S, Inomata M, Mizusawa J, Katayama H, Watanabe M, Yamamoto S, et al. Survival outcomes following laparoscopic versus open D3 dissection for stage II or III colon cancer (JCOG0404): a phase 3, randomised controlled trial. Lancet Gastroenterol Hepatol. 2017;2:261-8.

11. Edge SB, Compton CC. The American Joint Committee on Cancer: the 7th edition of the AJCC cancer staging manual and the future of TNM. Ann Surg Oncol 2010;17:1471-4.

12. Nakafusa Y, Tanaka T, Tanaka M, Kitajima Y, Sato S, Miyazaki K. Comparison of multivisceral resection and standard operation for locally advanced colorectal cancer: analysis of prognostic factors for short-term and long-term outcome. Dis Colon Rectum. 2004;47:2055-63.

13. Mohan HM, Evans MD, Larkin JO, Beynon J, Winter DC. Multivisceral resection in colorectal cancer: a systematic review. Ann Surg Oncol. 2013;20:2929-36.

14. Bretagnol F, Dedieu A, Zappa M, Guedj N, Ferron M, Panis Y. T4 colorectal cancer: is laparoscopic resection contraindicated? Colorect Dis 2011;13:138-43.

15. Ng DC, Co CS, Cheung HY, Chung CC, Li MK. The outcome of laparoscopic colorectal resection in T4 cancer. Colorect Dis. 2011;13:e349-e52.

16. Huh JW, Kim HR. The feasibility of laparoscopic resection compared to open surgery in clinically suspected T4 colorectal cancer. J Laparoendosc Adv Surg Tech A. 2012;22:463-7. 
17. Kim KY, Hwang DW, Park YK, Lee HS. A single surgeon's experience with 54 consecutive cases of multivisceral resection for locally advanced primary colorectal cancer: can the laparoscopic approach be performed safely? Surg Endosc. 2012;26:493-500.

18. Vignali A, Ghirardelli L, Di Palo S, Orsenigo E, Staudacher C. Laparoscopic treatment of advanced colonic cancer: a casematched control with open surgery. Colorect Dis. 2013;15:944-8.

19. Shukla PJ, Trencheva K, Merchant C, Maggiori L, Michelassi F, Sonoda T, et al. Laparoscopic resection of T4 colon cancers: is it feasible? Dis Colon Rectum. 2015;58:25-31.

20. de'Angelis N, Vitali GC, Brunetti F, Wassmer CH, Gagniere C, Puppa G, et al. Laparoscopic vs. open surgery for T4 colon cancer: a propensity score analysis. Int J Colorect Dis. 2016;31:1785-97.

21. Kim IY, Kim BR, Kim YW. The short-term and oncologic outcomes of laparoscopic versus open surgery for T4 colon cancer. Surg Endosc. 2016;30:1508-18.

22. Chan DK, Tan KK. Laparoscopic surgery should be considered in T4 colon cancer. Int J Colorect Dis 2017;32:517-20.

23. Moug SJ, Saldanha JD, McGregor JR, Balsitis M, Diament RH. Positive lymph node retrieval ratio optimises patient staging in colorectal cancer. Br J Cancer. 2009;100:1530-3.

24. Ceelen W, Van Nieuwenhove Y, Pattyn P. Prognostic value of the lymph node ratio in stage III colorectal cancer: a systematic review. Ann Surg Oncol. 2010;17:2847-55.

25. Rosenberg R, Engel J, Bruns C, Heitland W, Hermes N, Jauch $\mathrm{KW}$, et al. The prognostic value of lymph node ratio in a population-based collective of colorectal cancer patients. Ann Surg. 2010;251:1070-8.

26. Greenberg R, Itah R, Ghinea R, Sacham-Shmueli E, Inbar R, Avital S. Metastatic lymph node ratio (LNR) as a prognostic variable in colorectal cancer patients undergoing laparoscopic resection. Tech Coloproctol. 2011;15:273-9.

27. Greene FL, Stewart AK, Norton HJ. A new TNM staging strategy for node-positive (stage III) colon cancer: an analysis of 50,042 patients. Ann Surg 2002;236:416-21 (discussion 21).

28. Shirouzu K, Isomoto H, Kakegawa T, Morimatsu M. A prospective clinicopathologic study of venous invasion in colorectal cancer. Am J Surg 1991;162:216-22.

29. Dindo D, Demartines N, Clavien PA Classification of surgical complications: a new proposal with evaluation in a cohort of 6336 patients and results of a survey. Ann Surg 2004;240:205-13.

30. Veldkamp R, Gholghesaei M, Bonjer HJ, Meijer DW, Buunen M, Jeekel J, et al. Laparoscopic resection of colon Cancer: consensus of the European Association of Endoscopic Surgery (EAES). Surg Endosc. 2004;18:1163-85.

31. Elnahas A, Sunil S, Jackson TD, Okrainec A, Quereshy FA. Laparoscopic versus open surgery for T4 colon cancer: evaluation of margin status. Surg Endosc. 2016;30:1491-6.

32. Klaver CEL, Kappen TM, Borstlap WAA, Bemelman WA, Tanis PJ. Laparoscopic surgery for T4 colon cancer: a systematic review and meta-analysis. Surg Endosc. 2017. https://doi.org/10.1007/ s00464-017-5544-7 (published online).

33. Marusch F, Gastinger I, Schneider C, Scheidbach H, Konradt J, Bruch HP, et al. Experience as a factor influencing the indications for laparoscopic colorectal surgery and the results. Surg Endosc 2001;15:116-20.

34. Miyake Y, Nishimura J, Takahashi H, Haraguchi N, Hata T, Takemasa I, et al. The short-term outcomes of laparoscopic multivisceral resection for locally advanced colorectal cancer: our experience of 39 cases. Surg Today 2017;47:575-80.

35. National Comprehensive Cancer Network. Principles of pathologic review. Clinical Practice Guidelines in Oncology, Colon and Rectal Cancer, 2009, pp. 1-4. National Comprehensive Cancer Network, Fort Washington, MD.

36. Ishiguro S, Akasu T, Fujita S, Yamamoto S, Kusters M, Moriya Y. Pelvic exenteration for clinical T4 rectal cancer: oncologic outcome in 93 patients at a single institution over a 30 -year period. Surgery 2009;145:189-95.

37. Snaebjornsson P, Coupe VM, Jonasson L, Meijer GA, van Grieken NC, Jonasson JG. pT4 stage II and III colon cancers carry the worst prognosis in a nationwide survival analysis. Shepherd's local peritoneal involvement revisited. Int J Cancer 2014;135:467-78.

38. Cook MB, McGlynn KA, Devesa SS, Freedman ND, Anderson WF. Sex disparities in cancer mortality and survival. Cancer Epidemiol Biomark Prev. 2011;20:1629-37.

39. McArdle CS, McMillan DC, Hole DJ. Male gender adversely affects survival following surgery for colorectal cancer. Br J Surg. 2003;90:711-5.

40. Paulson EC, Wirtalla C, Armstrong K, Mahmoud NN. Gender influences treatment and survival in colorectal cancer surgery. Dis Colon Rectum. 2009;52:1982-91.

41. McMillan DC, Wotherspoon HA, Fearon KC, Sturgeon C, Cooke TG, McArdle CS. A prospective study of tumor recurrence and the acute-phase response after apparently curative colorectal cancer surgery. Am J Surg 1995;170:319-22.

42. Wichmann MW, Zellweger R, DeMaso CM, Ayala A, Chaudry IH. Mechanism of immunosuppression in males following trauma-hemorrhage. Critical role of testosterone. Arch Surg. 1996;131:1186-91 (discussion 91-2).

43. Wichmann MW, Ayala A, Chaudry IH. Male sex steroids are responsible for depressing macrophage immune function after trauma-hemorrhage. Am J Physiol. 1997;273::C1335-C40.

44. Kornprat P, Pollheimer MJ, Lindtner RA, Schlemmer A, Rehak $\mathrm{P}$, Langner $\mathrm{C}$. Value of tumor size as a prognostic variable in colorectal cancer: a critical reappraisal. Am J Clin Oncol 2011;34:43-9.

45. Wang Y, Zhuo C, Shi D, Zheng H, Xu Y, Gu W, et al. Unfavorable effect of small tumor size on cause-specific survival in stage IIA colon cancer, a SEER-based study. Int J Colorect Dis. 2015;30:131-7.

46. Takahashi T, Kato T, Kodaira S, Koyama Y, Sakabe T, Tominaga T, et al. Prognostic factors of colorectal cancer. Results of multivariate analysis of curative resection cases with or without adjuvant chemotherapy. Am J Clin Oncol 1996;19:408-15.

47. Wo JY, Chen K, Neville BA, Lin NU, Punglia RS. Effect of very small tumor size on cancer-specific mortality in node-positive breast cancer. J Clin Oncol. 2011;29:2619-27. 